\title{
ABRIGO IPÊS; USO DO DESIGN EMOCIONAL COMO FERRAMENTA PARA O DESENVOLVIMENTO DE NOVOS MOBILIÁRIOS URBANOS
}

\section{IPÊS BUS STOP: USING EMOTIONAL DESIGN AS A TOOL FOR THE DEVELOPMENT OF NEW URBAN FURNITURE}

Marcos Rinaldi Pereira Bernardo ${ }^{1}$ Leandro Lopes Pereira ${ }^{2}$ 


\section{Resumo}

O presente trabalho propõe a utilização do design emocional no desenvolvimento de um mobiliário urbano para a cidade de João Pessoa, buscando a conscientização da população para a preservação do patrimônio público, o desenvolvimento sustentável e a vida mais saudável. Estimular os usuários a usufruírem o meio urbano também é um dos objetivos. Para isso foram estudadas três teorias do design emocional, e utilizou-se o método do design thinking, um modelo de trabalho baseado na forma como o design é pensado. Através da aplicação de um método não convencional de projeto, associado às teorias do design emocional, foi possível chegar a um produto novo, com características e funções pouco exploradas atualmente, em se tratando de mobiliários urbanos. Dessa forma seria possível atender as atuais demandas da população da cidade de João Pessoa, bem como promover conceitos de preservação do mobiliário urbano, desenvolvimento sustentável e melhor qualidade de serviços públicos.

Palavras-Chave: mobiliário urbano, design emocional, design thinking.

\section{Abstract}

This paper proposes the application of emotional design in the development of urban furniture in João Pessoa city, aiming to increase awareness of local population of preserving public heritage and seeking mutual well-being, sustainable development and a healthier life. Another purpose is to stimulate the use of urban area. Therefore, three emotional design theories were studied, and the design thinking method was used. This model is based on the way the design is thought. By applying an unconventional design method, associated with emotional design theories, it was possible to reach a new product, which features and functions are currently underexplored, when urban furniture is considered. Thus it would be possible to achieve the current demands of João Pessoa city's population, while promoting concepts of urban furniture conservation, sustainable development, improving the quality of public services.

Keywords: urban furniture, emotional design, design thinking.

ISSN: 1808-3129
${ }^{1}$ Marcos Rinaldi Pereira Bernardo Universidade Federal da Paraiba marcosrinaldirct@hotmail.com
${ }^{2}$ Leandro Lopes Pereira Ipereira000@gmail.com 


\section{INTRODUÇÃO}

Todos os dias, milhares de pessoas transitam pelas ruas da cidade de João Pessoa, e se deparam com vários elementos que estão ali distribuídos para servi-los. Estes objetos são classificados como mobiliários urbanos, e possuem várias funções, tais como iluminação pública, informação, estética, etc.

Porém, é notório o desrespeito pelo patrimônio público, que fica evidente na degradação destes equipamentos, apesar dos esforços das autoridades que investem em reforma e modernização dos mesmos. Há ainda o acúmulo de lixo nas vias públicas, mesmo havendo lixeiras relativamente bem distribuídas.

Dentre os objetos de uso coletivo que mais sofrem depredação, estão as paradas de ônibus, cujos bancos, quando existem, estão quase sempre danificados, e suas colunas estão cobertas por papéis de anúncio, pichadas ou muito sujas.

As possiveis causas para a depredação dos mobiliários podem ser uso de materiais de baixa qualidade, tecnologias ultrapassadas e projetos mal executados. Também podemos identificar problemas de design de natureza diversa. Por exemplo, os bancos que não são confortáveis, na maioria das vezes expostos diretamente ao sol, as placas não sinalizam com precisão os nomes das ruas ou direções e as lixeiras não comportam a quantidade e o tipo de lixo despejado.

Com base nestas observações nos questionamos sobre como deveriam ser os mobiliários urbanos capazes de promover experiências prazerosas aos usuários do transporte público da cidade de João Pessoa, e dessa forma evitar a depredação dos mesmos.

Para responder a este e outros questionamentos relacionados, estudamos o design emocional, que explica como é forte o poder da estética e da funcionalidade dos objetos que nos rodeiam. Suas formas são capazes de despertar sentimentos de satisfação ou insatisfação, bem como nos fazer querer usá-los ou simplesmente deixá - los ali expostos, servindo além da sua função essencial, como objetos de decoração ou de desejo. $O$ desempenho das funções a que um produto se propõe também é um ponto chave na relação entre pessoa e objeto.

Se tudo funcionar bem, sem percalços, satisfazendo as expectativas, o sistema afetivo responde positivamente, trazendo prazer ao usuário. De maneira semelhante, se o design em si é elegante, bonito ou talvez brincalhão e divertido, mais uma vez o sistema afetivo reage positivamente. Em ambos os casos, atribuímos o nosso prazer ao produto, de modo que o elogiamos e, em casos extremos, tornamo-nos emocionalmente apegados a ele. Mas quando o comportamento é frustrante, quando o sistema parece ser recalcitrante, recusando-se a se comportar adequadamente, o resultado é afeto negativo, irritação, ou até pior, raiva. Nós culpamos o produto (NORMAN, 2009, p. 64).

Entende-se, portanto, que objetos mal resolvidos e mal distribuídos dentro do sistema, podem ser a causa de depredação e de comportamentos nocivos ou antissociais. Deste modo, o objetivo deste trabalho é desenvolver, utilizando os conhecimentos do design emocional, um novo mobiliário urbano, que atenda às necessidades dos usuários de maneira mais eficiente, diminuindo assim, a depredação dos equipamentos públicos, promovendo o bem-estar geral da população e o desenvolvimento sustentável. 


\section{FUNDAMENTOS TEÓRICOS Design Emocional}

Vivemos rodeados por objetos dos mais diversos, e com diferentes funções, desde aparelhos celulares, carros, cadeiras e escovas de dentes, panelas e obras de arte, cada um com o objetivo de nos ajudar na realização das tarefas que executamos ao longo do dia. Seria lógico então, que escolhêssemos os produtos a partir de nossas necessidades, e de como este ou aquele elemento pode nos ajudar. Mais lógico ainda que os produtos sejam construídos pensando na função e na usabilidade. Então, ao fim dos anos 1990, começaram a surgir os conceitos do design emocional.

Foi ao casar a Psicologia com o Design, que se pode então desenvolver metodologias de base para a certificação de que as emoções poderiam, de fato, ser provocadas por meio de produtos. Tal área é baseada em pesquisa direta com os usuários, aproximando assim, estes ao designer, para que seja possível observar se os objetivos emocionais foram alcançados. (TONETTO; XAVIER DA COSTA, 2011, p.132-140). Atualmente, é possível encontrar muitos estudos e publicações sobre o assunto, e alguns autores, inclusive, são muito conhecidos e influentes.

Um dos principais autores, certamente o mais conhecido, em seu livro "Design Emocional" apresenta os aspectos psicológicos da emoção, buscando explicar de maneira objetiva as formas como se processa o funcionamento do pensamento humano e qual a sua relação com os objetos. Segundo Norman (2009), o pensamento é processado em três níveis distintos, que são influenciados por diferentes estímulos.

\footnotetext{
No nível visceral temos as respostas automáticas aos estímulos. A parte do cérebro que controla esse nível está ligado diretamente aos músculos, de sorte que, se o animal está em uma situação de risco ou incômoda, todo seu corpo se tenciona para que ele possa fugir, atacar, etc. Já no caso de uma situação confortável, o animal pode relaxar e aproveitar. O nível comportamental é o responsável pela resolução de problemas simples, onde através da análise da situação, o cérebro pode alterar o comportamento. No caso dos humanos, é onde tarefas rotineiras como dirigir, pintar ou executar uma música em um instrumento musical são processadas. Esse nível é ainda, inconsciente, de maneira que você pode dirigir seu carro subconscientemente enquanto pensa sobre um assunto qualquer. Por último, tem-se o nível reflexivo, que é onde os humanos conseguem pensar sobre suas próprias ações, aprender novos conceitos e fazer generalizações sobre o mundo (NORMAN, 2009, p.43).
}

Os três níveis de processamento cerebral, interagem entre si, de maneira que os processos podem começar nos níveis mais primitivos do cérebro, ativando os níveis superiores, ou podem começar nos níveis superiores e trazidos para os inferiores. Ou seja, os estímulos podem ativar o visceral, e a partir daí desencadear reações no nível comportamental, e até no reflexivo. O contrário também acontece, sendo uma reflexão ativando os níveis inferiores, comportamental e visceral. Seria o papel do designer então, projetar pensando nos três níveis do processamento cerebral, e na maneira como um pode influenciar o outro durante o uso do produto final.

De maneira resumida, Norman (2009) considera que do ponto de vista do projeto, o design visceral está ligado à aparência, o design comportamental diz respeito 
ao desempenho e o prazer no uso, e o design reflexivo está associado à autoimagem, satisfação pessoal e lembranças. Podemos utilizar o quadro abaixo para compreender de maneira simplificada, as relações entre design e os níveis de processamento:

\begin{tabular}{|c|c|c|}
\hline Visceral & Aparência & $\begin{array}{c}\text { Formas, cores e } \\
\text { texturas; }\end{array}$ \\
\hline Comportamental & Uso & $\begin{array}{c}\text { Usabilidade, faci- } \\
\text { lidade de compreen- } \\
\text { são, como o produto é } \\
\text { fisicamente sentido; }\end{array}$ \\
\hline Reflexivo & Mensagem & $\begin{array}{c}\text { Memória, au- } \\
\text { toimagem, significado; }\end{array}$ \\
\hline
\end{tabular}

Tabela 1: níveis de processamento x design. Adaptado de NORMAN (2009).

Norman (2009), lista ainda, uma série de estímulos que causam afeto positivo ou negativo automático, e que podem ser usadas como referência para criação de novos conceitos de produtos.

\begin{tabular}{|r|l|}
\hline \multicolumn{1}{|c|}{ Afeto positivo } & \multicolumn{1}{c|}{ Afeto negativo } \\
\hline Lugares aquecidos e bem ilumi- & \multicolumn{1}{|c|}{ Alturas; Sons altos e luzes mui- } \\
nados; Clima temperado; Sabores e & to intensas; Objetos pairando no ar; \\
odores doces; Cores alegres de ma- & Calor ou frio extremos; Escuridão; \\
tizes intensamente saturadas; Sons & Terreno plano, vazio; Terreno denso; \\
tranquilizadores, melodias e ritmos & Multidões; Cheiros de podridão, ali- \\
simples; Música e sons harmoniosos; & mentos em decomposição; Sabores \\
Carícias; Rostos sorridentes; Cadên- & amargos; Objetos pontiagudos; Sons \\
cias ritmadas; Pessoas "atraentes"; & rangentes; Corpos deformados; Ser- \\
Objetos simétricos; Objetos lisos e e & pentes e aranhas; Fezes humanas (e \\
arredondados; Sensações, formas e e & seu cheiro); Fluidos corporais de ou- \\
sons "sensuais". & tras pessoas; Vômito. \\
\hline
\end{tabular}

Tabela 2: estímulos positivos e negativos automáticos. Adaptado de NORMAN (2009).

Já para os níveis mais complexos, comportamental e reflexivo, são exigidos um maior planejamento e observação do público alvo do projeto. Esses processos envolvem respectivamente as necessidades de cada pessoa e a cultura e memória de uma determinada população. Logo, para o designer projetar buscando atingir esses níveis mais complexos, é de extrema importância uma imersão no universo funcional (nível comportamental), cultural, histórico e simbólico (nível reflexivo) do público alvo.

Existem, claro, outras formas de se interpretar as emoções e relacioná-las com o design e os objetos. Por exemplo, os quatro prazeres de Patrick Jordan. Jordan (2000), fala sobre a constante busca pelo prazer característica dos humanos, e que, como consequência disto, os objetos por nós utilizados são fontes de satisfação. 


\begin{tabular}{|c|l|}
\hline Prazer fisiológico & $\begin{array}{l}\text { Está relacionado ao corpo. Os } \\
\text { sentidos (tato, olfato, visão e gusta- } \\
\text { ção) e o prazer sensual. }\end{array}$ \\
\hline Prazer social & $\begin{array}{l}\text { Diz respeito a interação social, } \\
\text { conversar, obter reconhecimento ou } \\
\text { status. Fazer parte de um grupo de } \\
\text { pessoas em um evento público. }\end{array}$ \\
\hline Prazer psicológico & $\begin{array}{l}\text { Refere-se aos prazeres de exe- } \\
\text { cutar uma tarefa, relaxamento ou } \\
\text { excitação. Influenciado pela perso- } \\
\text { nalidade de cada pessoa. Pessoas } \\
\text { práticas preferem designs racionais. } \\
\text { Pessoas criativas ou extravagantes } \\
\text { preferem componentes emocionais } \\
\text { fortes. }\end{array}$ \\
\hline Prazer ideológico & $\begin{array}{l}\text { Vem da combinação dos valo- } \\
\text { res agregados ao produto e os valo- } \\
\text { res pessoais do usuário. Envolve as } \\
\text { dimensões estéticas e valores morais. }\end{array}$ \\
\hline
\end{tabular}

Tabela 3: os quatro prazeres de Jordan.

Outra perspectiva é apresentada por Faggiani (2006). A autora comenta sobre os aspectos simbólicos do design, e do papel do designer na implementação de significados aos produtos. O seu trabalho dá especial atenção ao desenvolvimento dos produtos de luxo. Segundo a autora, uma das principais funções do designer é atribuir significado em vários níveis, tais como segurança, facilidade de uso e prestígio. $\mathrm{A}$ autora, acredita que ao criar produtos deve-se abordar os aspectos comportamentais e que para isso o objeto não pode ser visto como neutro, separado do seu contexto social e funcional.

\begin{tabular}{|c|l|}
\hline $\begin{array}{c}\text { Valor da raridade, da origem ou } \\
\text { material }\end{array}$ & $\begin{array}{l}\text { O luxo tem relação com rarida- } \\
\text { de, restrição e o incomum. O luxo é } \\
\text { uma distinção. }\end{array}$ \\
\hline Valor cultural e histórico & $\begin{array}{l}\text { A tradição aqui tem papel de } \\
\text { agregar valores simbólicos aos pro- } \\
\text { dutos. Diz respeito a valorizar as raí- } \\
\text { zes, estilos e valores culturais. He- } \\
\text { rança, reconhecimento e tradições } \\
\text { históricas. }\end{array}$ \\
\hline
\end{tabular}




\begin{tabular}{|c|c|}
\hline Valor afetivo e subjetivo & $\begin{array}{c}\text { Esse valor se refere ao conforto } \\
\text { e à qualidade. Trata-se da realização } \\
\text { de um sonho, um desejo. O luxo não } \\
\text { está associado a moda, mas ao esti- } \\
\text { lo, a alta costura, roupas de marca e } \\
\text { produtos assinados. }\end{array}$ \\
\hline $\begin{array}{c}\text { Valor do design: forma e apa- } \\
\text { rência } \\
\text { dade }\end{array}$ & $\begin{array}{l}\text { É o valor da aparência em } \\
\text { si. Segundo a autora, o visual é } \\
\text { determinante e decisivo para o } \\
\text { sucesso do produto no mercado. }\end{array}$ \\
\hline Valor ecológico dos materiais & $\begin{array}{l}\text { O valor da marca é o caminho } \\
\text { para o reconhecimento de valor. } \\
\text { Uma marca notória é sinônimo de } \\
\text { qualidade, e os produtos podem até } \\
\text { ser copiados, mas a marca é única. }\end{array}$ \\
\hline $\begin{array}{l}\text { zação do eco design, seguindo as } \\
\text { tendências mundiais do desenvolvi- } \\
\text { mento sustentável, da valorização da } \\
\text { diversidade biológica e cultural. }\end{array}$ \\
\hline
\end{tabular}

Tabela 4: o poder do design.

\section{Metodologia}

O método utilizado no presente trabalho foi o design thinking. Este é um processo baseado na maneira como o design é pensando, desde a identificação do problema ou oportunidade, passando pela coleta de informações, criação e escolha de soluções, até a implementação do projeto (AMBROSE: HARRIS, 2011). Segundo os autores

O design é um processo interativo, e o design thinking, o modo como o design é pensado, está presente em cada etapa da jornada que começa com o briefing do cliente e termina com o trabalho pronto (AMBROSE: HARRIS, 2011).

O processo de design, segundo os autores, pode ser dividido em sete etapas, que são definir, pesquisar, gerar ideias, selecionar, testar protótipos, implementar e aprender. Como complemento, foram acrescentadas sub etapas baseadas em outras bibliografias, para que se possa obter o máximo de informações e melhores resultados.

No caso da etapa de pesquisa, fez-se um cruzamento do design thinking com o método de projeto proposto por Löbach (2001). Segundo o último, deve-se realizar 
um conjunto de análises que ajudarão o designer a conhecer melhor o problema, bem como o público alvo, os concorrentes e soluções já existentes. De acordo com os resultados das análises, constrói-se um conjunto de exigências e recomendações para o novo produto.

Com as diretrizes estabelecidas, buscamos referências emocionais, de acordo com as teorias do design emocional, a fim de criar conceitos para o produto desejado. Foram exploradas alternativas relacionadas a cultura, história e a natureza da cidade. A partir disto, selecionamos os melhores conceitos e alternativas, até que se chegue a solução final.

\section{DESENVOLVIMENTO}

\section{Definição}

O problema identificado foi a relação entre a população com o mobiliário urbano da cidade de João Pessoa. A falta de qualidade dos serviços atendidos por esses produtos e a depredação dos mesmos.

Possíveis causas para estas questões, podem ser as deficiências projetuais, falta de ligação emocional entre usuários e objetos e a não adaptação destes à cultura local. A proposta é resolver esta deficiência através dos princípios do design emocional.

\section{Análises}

Na segunda etapa foram realizadas as análises de problema, necessidade, desenvolvimento histórico, relação social, mercado e de legislação e normas. Estas foram feitas através de estudo bibliográfico, de campo e fotográfico.

Verificou-se que o problema identificado provoca vários questionamentos, como por exemplo, a razão de os objetos serem depredados, mesmo estando ali para servir a população, e como o seu uso inadequado pode levar a sua deterioração ou prejuízo ao usuário. Observou-se que o mobiliário que possui o maior número de unidades com defeito, são os abrigos de pontos de ônibus. Nestes, além das más condições físicas, identificou-se alguns problemas de projeto, como a falta de indicação das linhas de ônibus que passam em cada ponto e os seus horários, a precariedade da proteção contra sol e chuva, à noite. Outro problema é que não existe iluminação própria, ou seja, os abrigos dependem da iluminação pública unicamente, ficando por muitas vezes em locais escuros e dessa forma causando sensações negativas nos usuários (ver tabela 2).

Em função do número de unidades danificadas e pela complexidade do serviço atendido que foram identificados durante a análise do problema, estabelecemos como objeto de estudo do trabalho, os abrigos de ônibus da cidade de João Pessoa. Assim as demais análises foram feitas especificamente sobre esses elementos urbanos. 
O transporte público em João Pessoa, é utilizado atualmente por aproximadamente 281.299 passageiros. Por mês a média chega a 8.438.995 passageiros, segundo dados da Superintendência de Mobilidade Urbana - SEMOB - (2013). Fica claro que os abrigos de pontos de ônibus, são intensamente utilizados todos os dias, e mesmo que por poucos minutos, influenciam de alguma maneira a vida dos usuários.

O abrigo de ponto de ônibus deve servir às pessoas de ambos os sexos, de todas as classes sociais e idades. O maior número de usuários, entretanto, são os estudantes de ensino médio e universitários, além de trabalhadores de classe média, ou que estão começando suas carreiras e ainda precisam do sistema público de transportes para se deslocar. Os idosos também são observados como usuários principais, pois possuem gratuidade de passagem.

Um público alvo secundário identificado são os motoristas, ciclistas e pedestres que observam os pontos de ônibus como elementos de ornamentação da paisagem urbana e de sinalização.

Após a análise da necessidade e da relação social, foram estudadas as relações do mobiliário com o meio ambiente, e as interações do mesmo com os elementos naturais (sol, chuva, vento e maresia), e a relação estético funcional com as paisagens naturais e urbanas. Por ser uma cidade litorânea, muitos abrigos estão instalados ao longo da orla marítima, e por isso sujeitos a fortes ventos e a maresia. Sendo assim, existe a necessidade da utilização de materiais que sejam resistentes às intempéries e de configurações estruturais que protejam os usuários dos elementos naturais.

Estudou-se, a história dos abrigos de ônibus desde o surgimento dos transportes públicos urbanos, e seu desenvolvimento ao longo do tempo no mundo e no Brasil. Foram coletadas uma série de fotografias, e realizado estudos de caso de projetos implementados recentemente nas cidades do Rio de Janeiro e São Paulo.

As funções foram analisadas de maneira aprofundada, e elencadas hierarquicamente em função principal e secundárias. Também foram analisadas as configurações estéticas e estruturais dos abrigos presentes em João Pessoa.

A partir das análises realizadas, foram descritas as exigências para o novo produto. Estas serviram como referência para a criação dos conceitos e sua posterior escolha. São elas: sinalizar com precisão os pontos de ônibus, indicar quais linhas passam por aquele ponto e seus itinerários e horários, oferecer segurança e conforto aos usuários, proteger contra as intempéries (sol, vento, chuva, etc.), se relacionar harmonicamente com as paisagens naturais e urbanas bem como criar uma conexão cultural e histórica com a cidade e utilizar tecnologias sustentáveis.

\section{Geração de ideias}

Os conceitos foram gerados, buscando inspiração na cultura e paisagens de João Pessoa, observando-se ao mesmo tempo, os princípios de design emocional. De acordo com as diretrizes estabelecidas, funções foram bastante exploradas nas alternativas, pois constatou-se a falta de indicativos das linhas e horários dos ônibus, o que gera uma grande dificuldade ao público alvo. Além disso, de acordo com o design emocional, o desempenho e o tipo de função são fatores decisivos para o sucesso de um produto. 
As inspirações dos conceitos da figura 1 foram as ondas do mar, os parques e praças da cidade e as flores. Tentou-se fugir de temas comumente utilizados para desenvolver projetos na cidade, como o farol do Cabo Branco e a Estação Ciência.

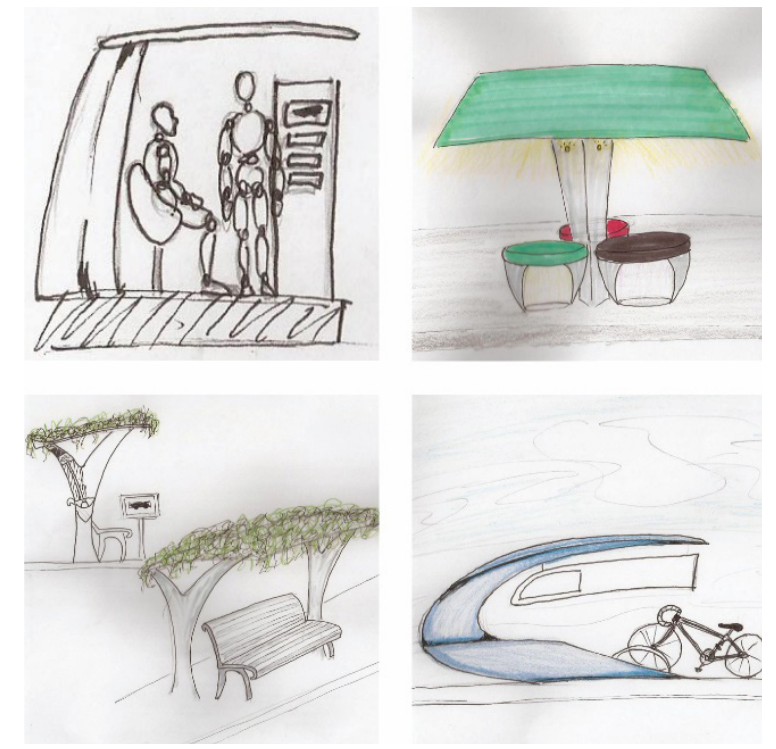

Figura 1 - conceitos gerados.

O último conceito gerado foi concebido a partir de um cartão postal menos frequentado por turistas, mas com grande conteúdo histórico, social e político. Trata-se do parque Solón de Lucena, localizado no centro da cidade, próximo ao centro histórico, onde João Pessoa começou a se desenvolver.

Naquele parque, existe uma grande quantidade de ipês amarelos, que se tornaram um símbolo da primavera pessoense. Destes, foram captadas referências formais, cores e funções (através da biônica, técnica que usa a biologia para encontrar soluções em design e engenharia).
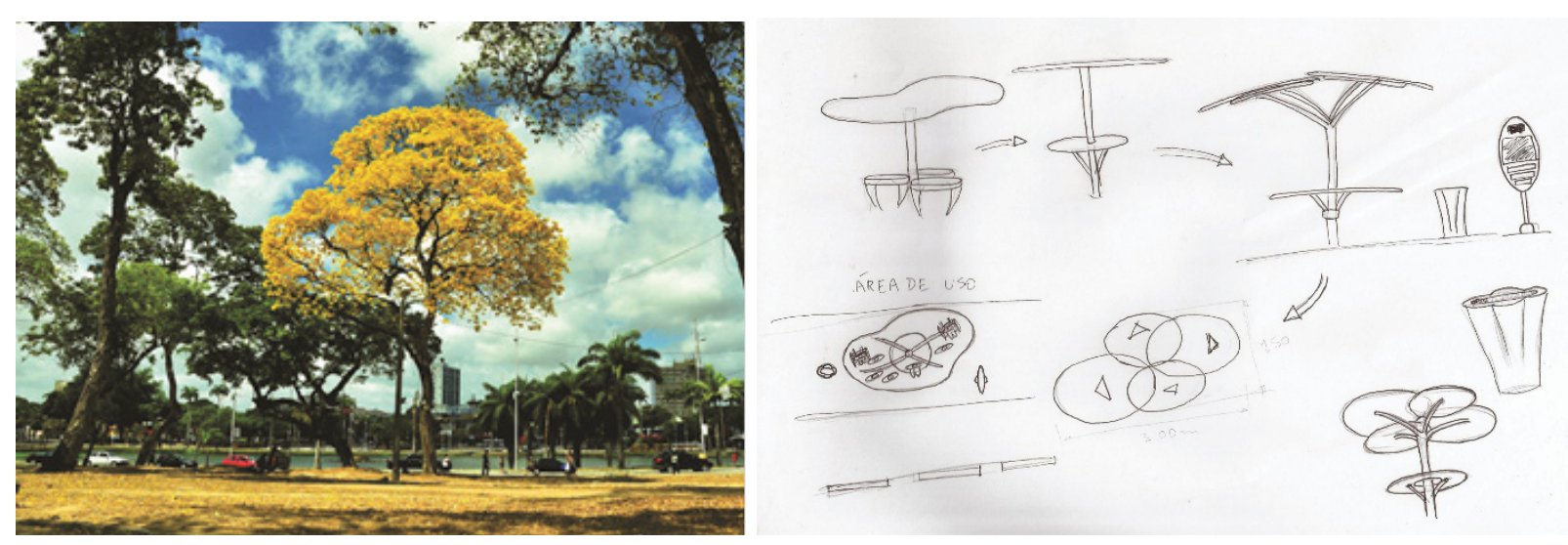

Figura 2 - ipê amarelo, parque Solón de Lucena.

Figura 3 - rascunhos sobre o conceito ipês. 


\section{Testar protótipos}

Dentre os conceitos gerados, foram escolhidos os três que melhor se adequaram aos requisitos gerados após as análises e deles foram executados modelos tridimensionais virtuais em escala real, como proposto pela metodologia.

Através destes pudemos observar melhor sua geometria, aplicação de materiais e fazer um breve estudo ergonômico. Também foram estudadas as possibilidades de circulação de pessoas, e a capacidade de abrigo de cada conceito.

A quantidade de assentos e acessibilidade também foram analisadas. Todos os testes foram realizados para garantir que o conceito final seja capaz de atender aos requisitos gerados na etapa de pesquisa.
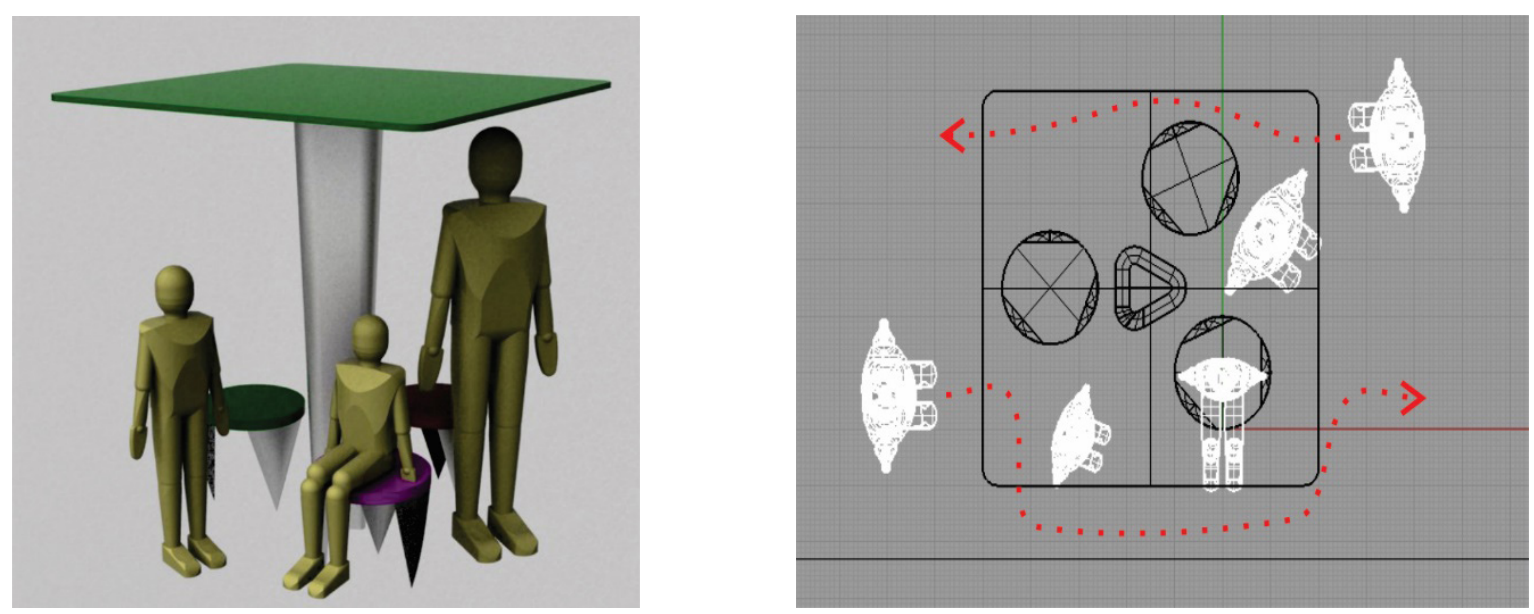

Figura 4 - modelo tridimensional 1

Figura 5 - estudo de circulação do modelo 1.
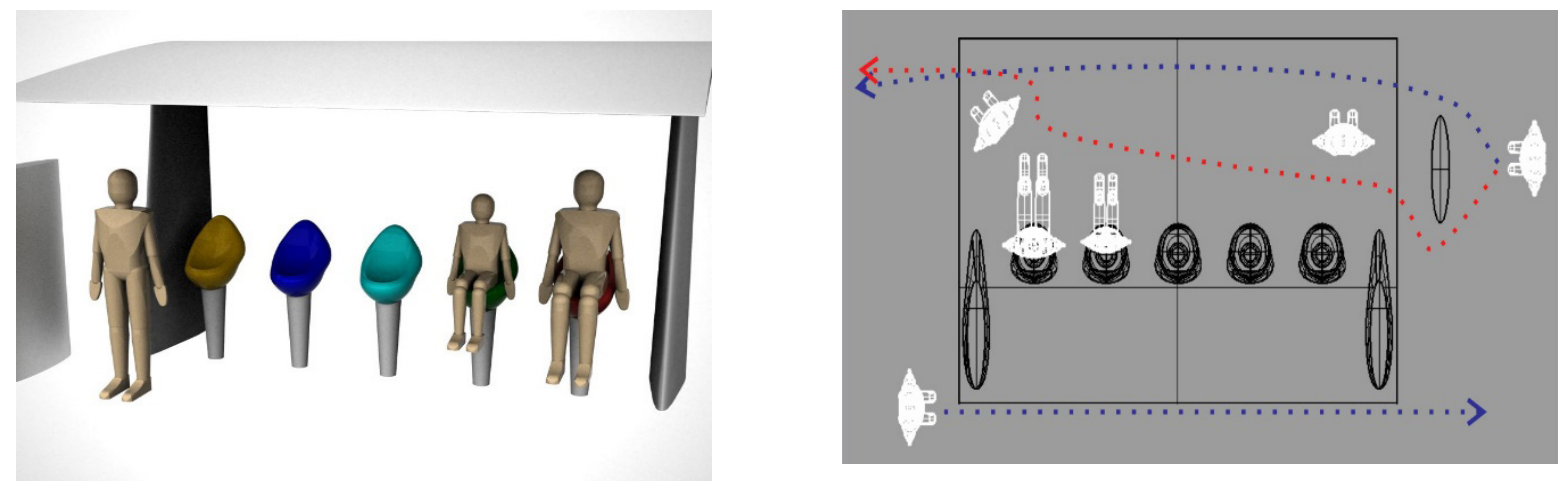

Figura 6 - modelo tridimensional 2.

Figura 7 - estudo de circulação do modelo 2. 


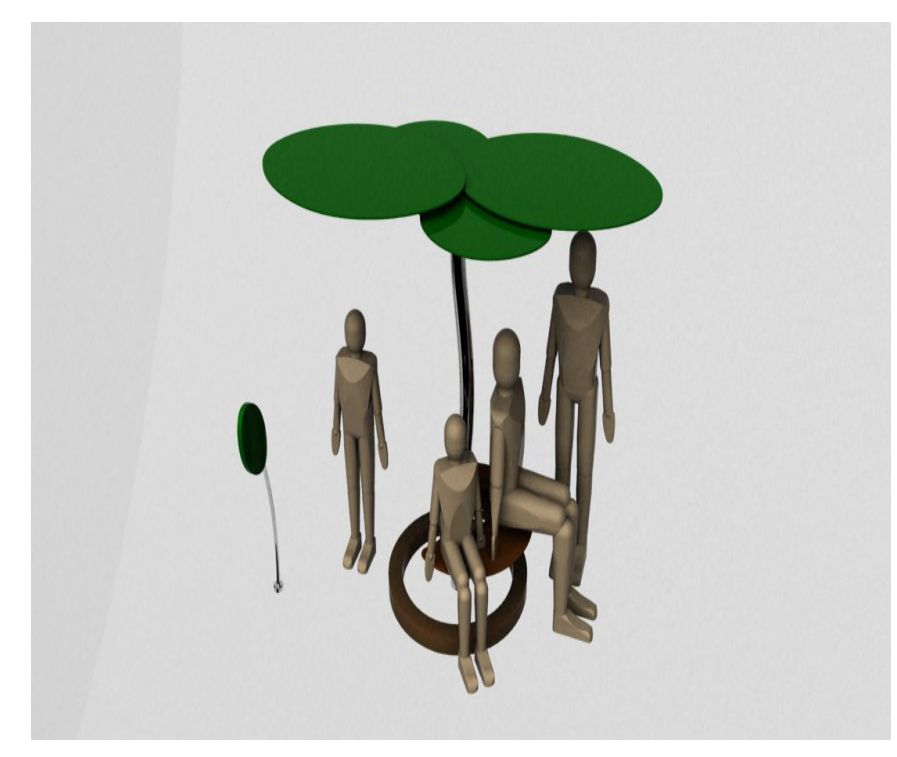

Figura 8 - modelo tridimensional 3.

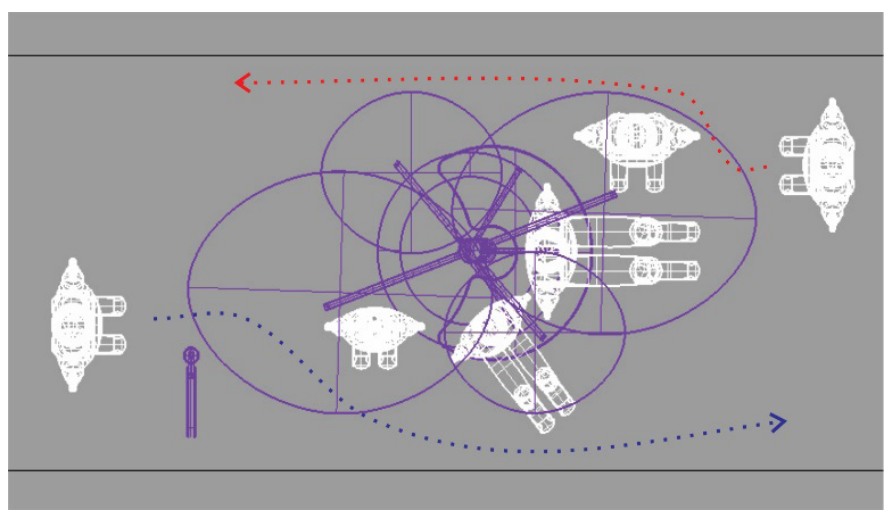

Figura 9 - estudo de circulação do modelo 3.

\section{Selecionar}

Com os modelos virtuais, buscou-se analisar critérios como a ergonomia, circulação de pessoas, simulação de texturas e estudo de cores. Os resultados destes testes tiveram um peso considerável para a seleção, mas o conceito, a relação histórica e cultural e os aspectos viscerais foram da mesma forma analisados. Assim conseguimos uma alternativa que estimula de maneira satisfatória os três níveis de processamento cerebral: visceral, através das cores, formas e texturas. Comportamental, pela realização das tarefas e reflexivo induzido pela relação com a história e cultura da cidade.

O conceito escolhido foi chamado de "ipês", e é inspirado - como apresentado na etapa de criação - nos ipês amarelos do parque Solón de Lucena, no centro da capital paraibana. Este representa um símbolo muito forte da cidade, criando uma relação à nível reflexivo com os habitantes da cidade.

Para os turistas, introduz uma identidade reconhecível, sempre que for visualizado em fotos, vídeos ou qualquer outro tipo de mídia e publicidade.

Sua estrutura é simples e composta por partes intercambiáveis, proporcionando uma melhor manutenção e troca de peças. 


\section{Implementar}

Com o conceito final selecionado, foram realizados os detalhamentos finais. Funções foram definidas e agregaram-se características de outros modelos.

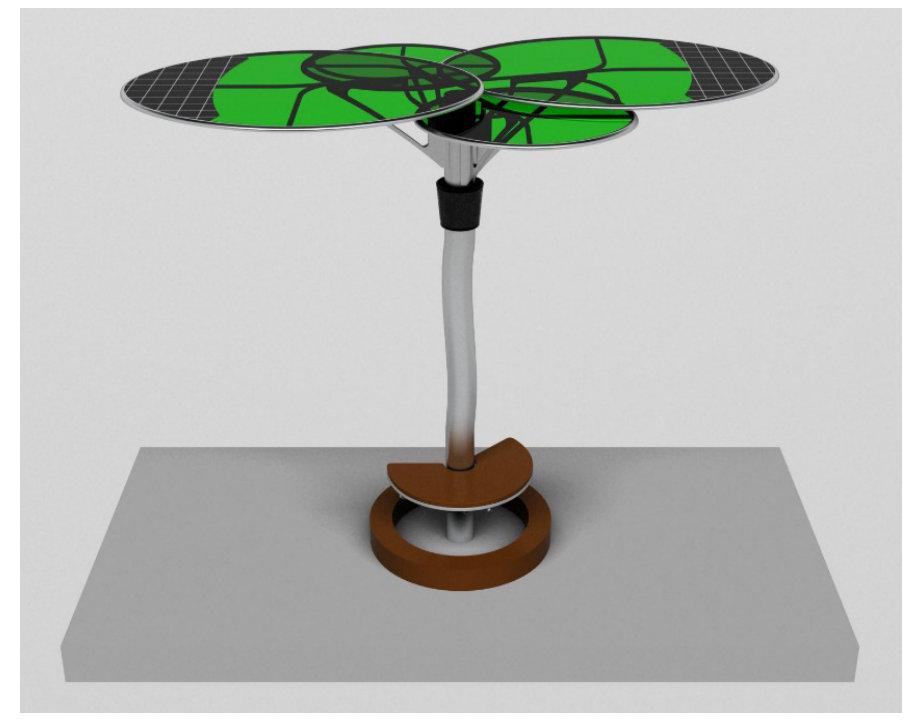

Figura 10 - conceito final Ipês.

O abrigo de ônibus deverá atender às necessidades dos usuários, tais como sinalização de parada de ônibus, proteção contra sol e chuva e descanso. Porém, pensando em criar uma relação emocional com os usuários, foram atribuídas funções e características extras.

Suas formas orgânicas, estimulam positivamente o nível visceral, e o conceito relacionado a história e tradição da cidade, estimula o nível reflexivo dos usuários.

Durante as análises, pudemos observar a falta de informações sobre as linhas e itinerários dos ônibus, por isso o abrigo possuirá um display digital para transmitir essas informações. A tecnologia OLED (organic light-emitting diode), permite criar um mostrador digital em formato de tronco de cone, preso ao poste central, informando em tempo integral, horários, itinerários (mapa) e duração dos percursos. Informações extras como previsão do tempo, notícias e publicidade também poderão ser transmitidas.

Tudo isto, conectado à um sistema central, com acesso a internet, gerenciado pela empresa responsável por transportes públicos, ou a própria prefeitura, seria capaz de melhorar consideravelmente a qualidade dos serviços atualmente oferecidos, assim gerando uma resposta positiva à nível comportamental.

Tais tecnologias já são utilizadas em vários países, e, portanto, não apresentam grandes desafios tecnológicos de implementação em cidades brasileiras, e promoveriam um grande avanço no que diz respeito a serviços de transportes públicos. 


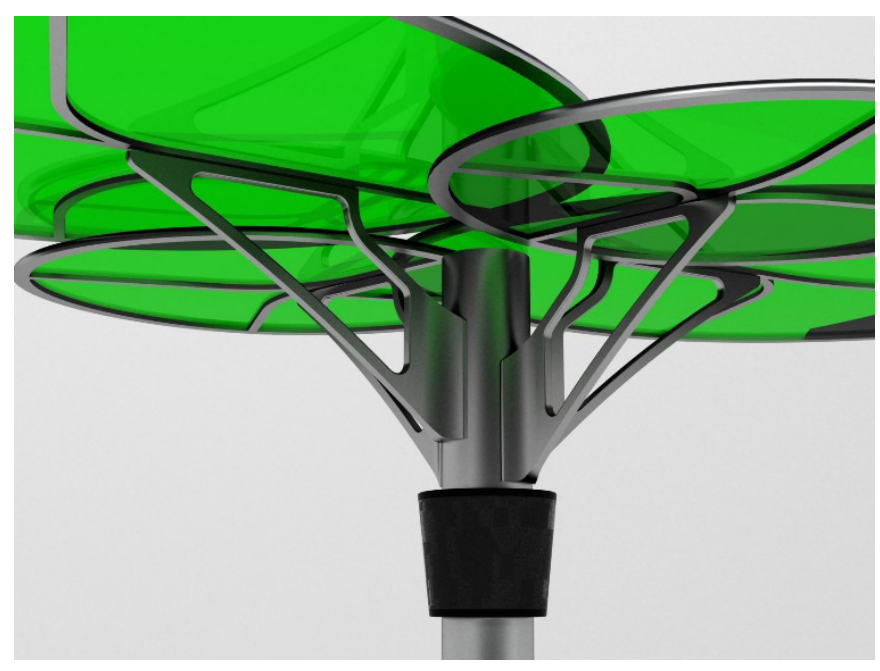

Figura 11 - display OLED.

Inspirado pela fotossíntese - processo pelo qual vegetais geram sua energia, utilizando a luz - o conceito Ipês possuí captadores de energia solar que alimentarão tomadas e plugues USB, para recarga de dispositivos móveis dos usuários, tais como telefones celulares e tablets.

Através da utilização de energias renováveis, a prefeitura será capaz de reduzir custos energéticos, pois além de ser usada nos abrigos, a energia solar também poderá ser utilizada em iluminação e outros serviços públicos.

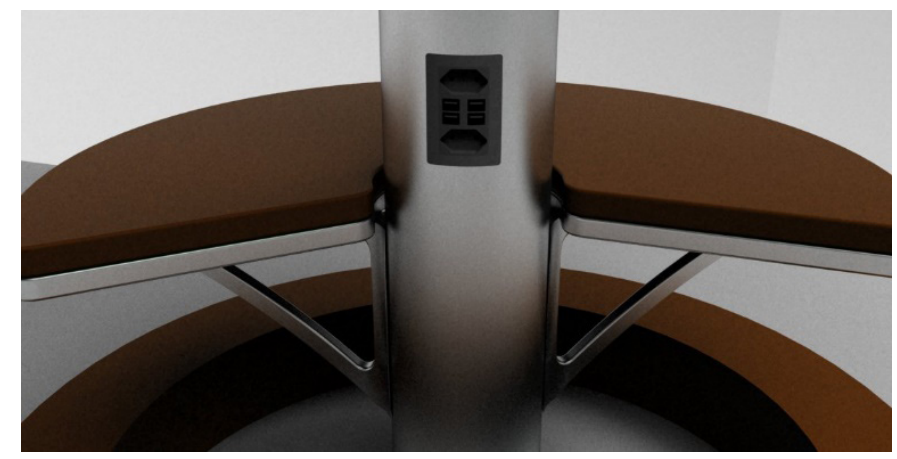

Figura 12 - tomadas para recarregar dispositivos portáteis.

Partindo de outra referência natural, a cobertura do abrigo possui formas orgânicas que lembram as folhas do ipê amarelo e é composta por quatro partes, para permitir as trocas de ar quente e frio, assim como as copas das árvores com seus galhos e grupos de folhas sobrepostas.

Construída em policarbonato translucido verde, com proteção anti-UV, a cobertura permite iluminação natural durante o dia, e mesmo a noite, a iluminação pública é suficiente para manter boa claridade sob o abrigo. A cor verde também estimula positivamente o nível visceral. 

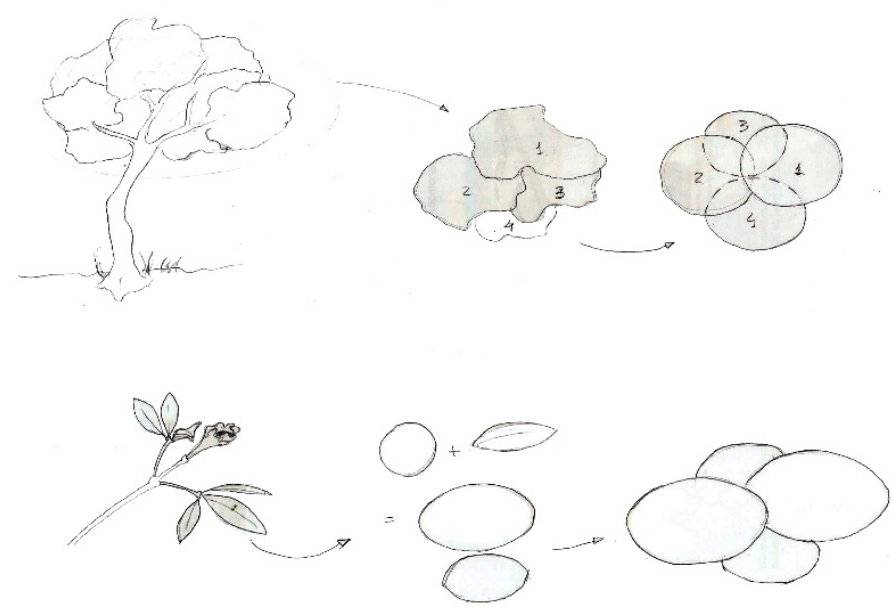

Figura 13 - referências formais (biomimetismo).

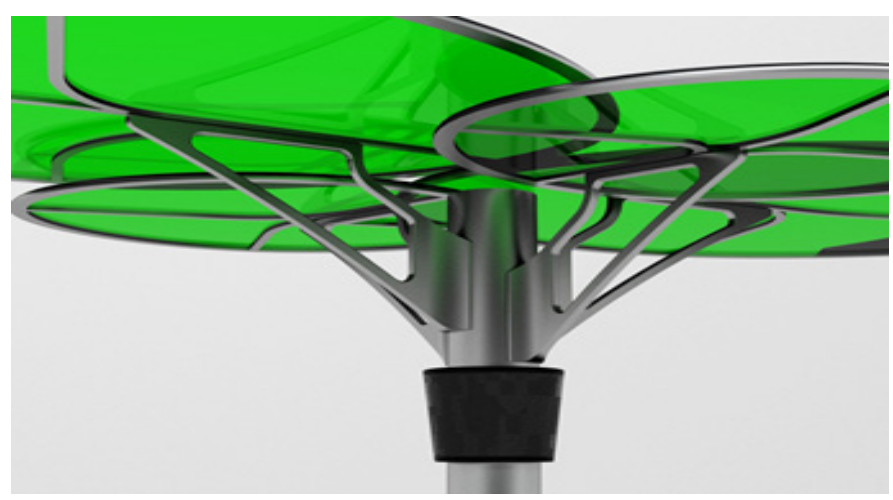

Figura 14 - cobertura composta por partes sobrepostas para permitir trocas de ar.

O banco tem formato semicircular, e está direcionado de maneira a proporcionar uma melhor visualização da via e consequentemente da chegada dos ônibus.

Ao longo da orla marítima, além dos elementos essenciais do abrigo, deverá ser instalada uma estrutura de proteção contra o vento, feito em policarbonato translúcido para não interferir na paisagem natural.

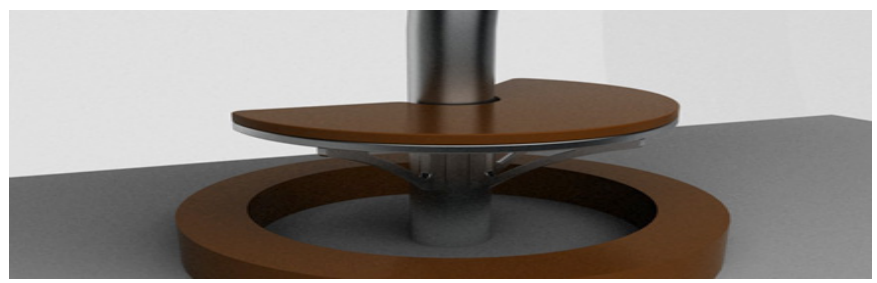

Figura 15 - banco semicircular direcionado. 


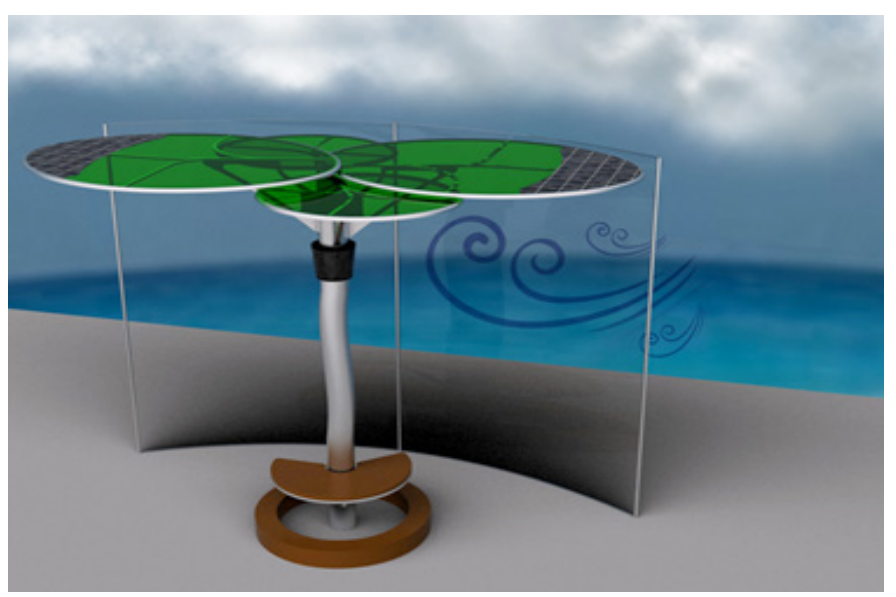

Figura 16 - quebra vento.

Em localidades onde existe um grande fluxo de usuários, como no Parque Solón de Lucena e na Universidade Federal, existe uma confluência de linhas de ônibus, tornando necessária a instalação de vários pontos de parada.

O formato do abrigo Ipês, permite instalá-los de forma alternada, para melhor visualização da rua, circulação de ar e iluminação. Essa função foi inspirada na forma como as árvores estão dispostas na natureza, e como suas copas se unem formando uma unidade visual única.
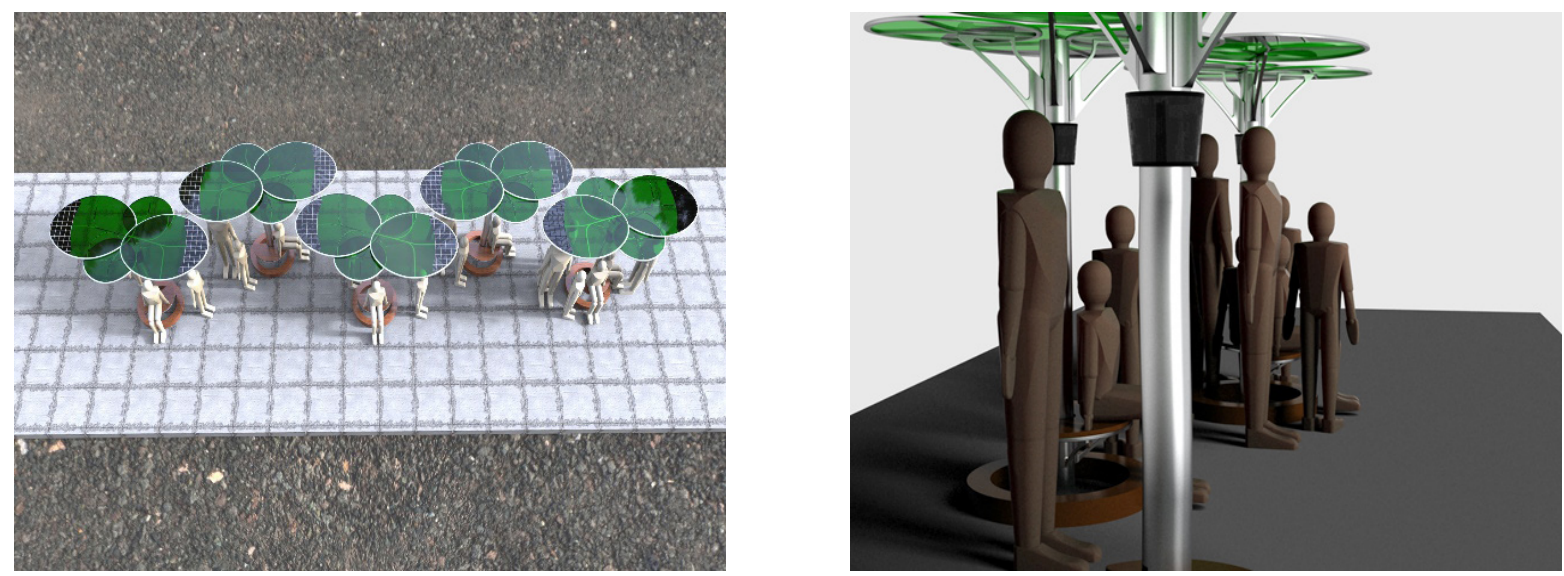

Figura 17 - múltiplos abrigos instalados em pontos de grande fluxo.

Figura 18 - visão em primeira pessoa.

\section{Aprendizado}

O projeto de design, é na verdade um processo contínuo de aprendizado e evolução, por isso, não deve ser arquivado após a implementação do mesmo. Este deve ser revisado e atualizado de tempos em tempos, para continuar satisfazendo seus usuários.

No caso do mobiliário urbano, pode-se realizar uma pesquisa periódica com os usuários, ouvindo suas possíveis reclamações e sugestões, e gerar um relatório que possa ajudar os designers e arquitetos a desenvolver as possíveis soluções e melhorias para o produto. Esta é uma tarefa fácil, pois sabemos exatamente onde o principal usuário se encontra, e pode-se contar ainda com os dados da ouvidoria da prefeitura, 
pesquisas nas redes sociais e dados estatísticos de outras secretarias e autarquias.

O presente artigo é baseado em um trabalho de conclusão de curso, e após o mesmo ser apresentado em defesa pública, foram realizadas algumas alterações, dando assim continuidade ao processo de design.

Existe ainda, intenção do mesmo ser apresentado junto à prefeitura e à autarquia de mobilidade urbana, bem como as empresas responsáveis pelos serviços de transporte público da cidade, e assim será realizada uma nova avaliação, sempre buscando a melhoria do projeto. 


\section{CONCLUSÃO}

O design emocional pode nos proporcionar um modelo diferenciado de projetar novos produtos. Através de sua proximidade com a psicologia, nos dá bases científicas poderosas para entender o funcionamento do pensamento e desejos dos usuários.

Estes conhecimentos associados à métodos objetivos de design, nesse caso, o design thinking, proporcionam um leque amplo de novas possibilidades em soluções para os mais diversos problemas identificáveis. O design emocional pode também, ajudar no reconhecimento de oportunidades de novos negócios, já que, diferente dos métodos tradicionais de projeto, busca entender profundamente a relação entre pessoas e objetos, e nos permite perceber que cada uma das características de um produto, pode além de resolver simples problemas, provocar o desejo e assim, conquistar o público alvo.

Neste trabalho, o design emocional foi utilizado para desenvolvermos um produto que, ao proporcionar prazer, conforto e segurança, bem como outros serviços aos usuários, busca diminuir ao máximo a depredação dos mobiliários urbanos, além de introduzir na população a ideia do uso de tecnologias sustentáveis, através da aplicação de energia solar para recarregar dispositivos móveis, e das formas inspiradas na natureza.

Após a finalização deste projeto, acredita-se que o processo de criação apresentado nos dá condições de explorar alternativas e características pouco convencionais, em se tratando de mobiliários urbanos e na promoção de melhores serviços públicos.

\section{REFERÊNCIAS}

AMBROSE, G.; HARRIS, P., 2011, "Design Thinking (Coleção Design Básico)", Bookman. FAGGIANI, K., 2006. "O poder do design: da ostentação à emoção", Thesaurus, Brasilia, 136, p. $65-72$.

JORDAN, P. 2000, apud Tonetto, L. M. e Xavier da Costa, F. C. 2011, "Design emocional; conceitos, abordagens e perspectivas de pesquisa", Strategic Design Research Journal, 4(3), p. 132-140.

LOBACH, B. "Design Industrial; bases para configuração dos produtos industriais" 2001. Edgard Blucher. São Paulo, p.143 - 155, cap. 8.

NORMAN, D., 2009, "Design emocional; porque adoramos (ou detestamos) os objetos do dia a dia" Rocco. Rio de Janeiro, 278, p. 64.

TONETTO, L. M. E XAVIER DA COSTA, F. C. 2011, "Design emocional; conceitos, abordagens e perspectivas de pesquisa", Strategic Design Research Journal, 4(3), p.132140. 